\title{
Impact of motor vehicle accidents on neck pain and disability in general practice
}

\author{
Cees J Vos, Arianne P Verhagen, Jan Passchier and Bart W Koes
}

\begin{abstract}
\section{Background}

High levels of continuous neck pain after a motor vehicle accident (MVA) are reported in cross-sectional studies. Knowledge of this association in general practice is limited.
\end{abstract}

Aim

To compare the differences in perceived pain and disability in patients with acute neck pain due to an MVA versus other self-reported causes. The secondary aim was to identify prognostic factors for continuous neck pain.

\section{Design of study}

Prospective cohort study with 1-year follow-up.

\section{Setting}

General practices in Rotterdam and its suburban region.

\section{Method}

Patients with non-specific acute neck pain were invited to participate. Questionnaires were collected at baseline and after $6,12,26$, and 52 weeks. The numerical pain-rating scale (NRS) and the neck disability index (NDI) were measured. Regression analysis was used to identify prognostic factors for continuous neck pain.

\section{Results}

A total of 187 patients were included. The MVA subgroup $(n=42)$ was significantly younger $(P=$ $0.007)$, reported more sick leave $(P=0.037)$, higher levels of headache $(P<0.001)$ and higher NDI scores at baseline $(P=0.018)$ but lower scores for previous neck pain $(P=0.015)$ compared to the remaining cohort. At follow-up the MVA subgroup had higher scores for continuous neck pain (63\% versus $40 \%$ ) and at the NDI (11.0 versus 7.1). After multivariate analysis 'pain in the upper part of the neck' (odds ratio [OR] = 1.6),

'duration of complaints at baseline longer than

2 weeks' (OR $=5.3)$, and an 'MVA' (OR $=5.3$ ) were significantly correlated with outcome.

\section{Conclusion}

Individuals exposed to MVAs constitute a relevant subgroup of patients with neck pain. An MVA and a longer duration of complaints are prognostic factors for continuous neck pain.

Keywords

disability; general practice; motor vehicle accidents; neck pain; prognostic factors.

\section{INTRODUCTION}

Neck pain is a common complaint. ${ }^{1}$ In a population survey, $66 \%$ of Saskatchewan adults experienced neck pain at some point in their lifetime and 54\% had done so in a recent 6-month period. ${ }^{2}$ Most reported figures on the prevalence of chronic pain in the general population lie between $15 \%$ and $19 \%$, with the figures for women being somewhat higher than those for men. ${ }^{3,4}$ In The Netherlands, Picavet et al reported a 1year prevalence of neck pain of $31.4 \%$, a point prevalence of $20.6 \%$, and a prevalence of chronic neck pain of $14.3 \%$ in the open population. ${ }^{5}$ The majority of patients reported pain at more than one site with a considerable overlap between different sites. ${ }^{5}$

A motor vehicle accident (MVA) is a frequently reported factor that might have a substantial impact on persistent neck pain and disability, ${ }^{6}$ although it is not the only risk factor. All types of neck trauma seem to be associated with chronic neck pain. ${ }^{3}$ The concept and prevalence of residual neck complaints caused by an accident-related injury is one of the most debated conditions in medicine. ${ }^{6}$ Although an MVA is not equal to a whiplash.

The most frequently reported complaint with whiplash is neck pain followed by headache. The incidence of whiplash varies between countries with

CJ Vos, MD, PhD, GP, AP Verhagen, PhD, senior researcher, BW Koes, PhD, professor of clinical research, Department of General Practice; J Passchier, professor of medical psychology, Department of Medical Psychology, Erasmus MC, University Medical Centre Rotterdam, the Netherlands.

Address for correspondence

Cees Vos, Department of General Practice, Erasmus Medical Centre, University Medical Centre Rotterdam,

PO Box 1738, 3000 DR Rotterdam. The Netherlands E-mail: c.vos@erasmusmc.nl

Submitted: 18 January 2008; Editor's response: 28 March 2008; final acceptance: 6 May 2008.

(c)British Journal of General Practice 2008; 58: 624-629.

DOI: $10.3399 /$ bjgp08X330762 
rates of 0.7 per 1000 inhabitants in Quebec, 1.0 per 1000 in Sweden, and 1.8 per 1000 in The Netherlands. ${ }^{7,8}$ In Saskatchewan, the incidence of reported whiplash injuries dropped $43 \%$ after the introduction of the no-fault system. ${ }^{9}$ The apparent discrepancy in incidence rates could be the result of the differences in jurisdiction in which the whiplash injuries were reported but, in general, incidence is thought to be about 1.0 per 1000 in Western societies. ${ }^{10}$

Some authors suggest that the prevalence of chronic pain in patients who have been involved in MVAs is the same as in the rest of the population, ${ }^{11}$ but cross-sectional studies consistently report that a history of neck injury is more common in patients with chronic neck pain. ${ }^{12}$ Although cross-sectional studies cannot prove a causal relationship, they can show that neck pain is more prevalent in individuals with a history of an MVA. ${ }^{2}$ Follow-up studies of selected groups of patients who have had a neck injury suggest that their risk of developing chronic neck pain is high. ${ }^{13}$

A remarkable contrast exists in reported recovery rates between studies based on patients' samples from insurance companies and clinical settings. The Quebec Task Force advocated that whiplash has a 'favourable' prognosis and concluded that $97 \%$ of patients recovered within 12 months after their MVA: ${ }^{14}$ recovery was defined as 'cessation of time-loss compensation'. A Canadian study also found that after just 1 year, $4 \%$ of patients had still not recovered; in this study 'the moment of closure of the claim for compensation' was used as the measure for recovery. ${ }^{15}$ However, in a review, Barnsley et al concluded that after 1 year between $14 \%$ and $42 \%$ of patients who had been involved in MVAs still had neck-pain complaints. ${ }^{10}$ It seems that the presented figures in the literature about the prognosis of whiplash highly depend on the definition used to constitute 'recovery', the jurisdiction system, and the setting in which the patients were selected.

Most patients recover from whiplash in the first 2-3 months after injury. ${ }^{10}$ Studies on recovery indicate that the outcome is twofold: either the neck pain will resolve in the first few months or it will persist with a high probability of becoming a chronic complaint., ${ }^{6,9}$ The chance of recovery is less favourable for women and decreases with age $-14 \%$ for every decade according to Harder et al. ${ }^{15}$

Longer-term (for example, after 5 years) recovery figures are comparable with the figures after 1-year follow-up..$^{13,16}$ The majority of patients in these studies reported hardly any change over the years but, if change occurs, deterioration outbalances improvement. Almost all studies available on the prognosis of whiplash are hospital based $;{ }^{17}$ thus they are referral based and, therefore, subject to case-

\section{How this fits in}

Neck pain as a consequence of a motor vehicle accident (MVA) is more prevalent than other self-reported causes. Reported disabilities from an MVA are also on a substantially higher level. Pain in the upper part of the neck and complaints that last for more than 2 weeks enhance the possibility of

experiencing long-lasting neck pain. In the first assessment, it is important to be aware of the dualism in presented causes (traumatic and non-traumatic) and their consequences for the clinical course of neck pain; as such, this particular sub-group deserves a more active assessment approach in daily practice.

selection bias. ${ }^{10}$ In a systematic review of prognosis, only two studies out of 29 were found with patients recruited from primary care practices. ${ }^{17}$

A substantial proportion of people who have been involved in an MVA experience long-term disability. In a postal survey in Sweden 17 years after the first examination, 55\% had residual disorders possibly due to the original accident. ${ }^{13}$ In a systematic review Ameratunga et al reported prevalence estimates of post-MVA disability varying from $2 \%$ to $87 \% .^{18}$

The objective of this study was twofold. The primary aim was to compare the differences in perceived pain and disability in patients with acute neck pain due to an MVA versus other self-reported causes, while the secondary aim was to identify prognostic factors for continuous neck pain. Both questions will be addressed from the primary care perspective.

\section{METHOD}

\section{Study population}

GPs working in Rotterdam and the suburban region were invited to participate in the study. The study design was a prospective cohort study with a follow-up period of 1 year. The initial aim was to include 200 patients. Patients were invited who had neck pain lasting no longer than 6 weeks to participate in the study. This could be neck pain occurring for the first time, or recurrent neck pain after a period free from pain that had lasted for at least 3 months. A generally accepted time-based classification of neck pain is threefold: acute (0-6 weeks), sub-acute (6-12 weeks), and chronic (>3 months). Additional inclusion criteria were:

- patients were aged above 18 years;

- the self-reported cause of the neck pain concerned the current episode; and

- patients had sufficient knowledge of Dutch to be able to complete written questionnaires.

Excluded were all patients with specific causes of neck pain (for example, known vascular or neurological disorders, neoplasms, rheumatic conditions, cervical disc herniations, or referred pain from internal organs). 
After oral consent, the GP handed over an envelope containing the baseline questionnaire, a patient information form concerning the content of the study, an informed consent form, and a prepaid return envelope. Only after having returned a completed baseline questionnaire as well as a written informed consent form were patients included in the study. The returned questionnaires were checked by the clinical research associate for completion, age, the duration of complaints, the pain-free interval, and both inclusion and exclusion criteria.

\section{Questionnaires}

The baseline questionnaire contained items on demographic variables, previous history, treatments for neck pain, duration of neck pain, cause of current neck complaints, previous and concomitant headache, radiating pain, smoking habits, and sudden onset of complaints. Patients scored the average severity of their neck pain on a numerical rating scale (NRS) ranging from 0 (no pain) to 10 (unbearable pain) and completed the neck disability index (NDI). From both instruments reliability and validity are well established..$^{19}$

The NDI is a 10-item disability questionnaire containing questions on three different domains: pain intensity (neck pain, headache), work-related activities (work, lifting, and concentration), and non-work related activities (personal care, reading, driving, sleeping, and recreation). Patients choose one out of six answer categories for each item describing the degree of disability from 0 (no activity limitation) to 5 (major activity limitation). The score for all items are added up, thus, the total score ranges between 0 and $50 .{ }^{19}$

\section{Table 1. Patient characteristics of the study population at baseline $(n=187)$.}

$n(\%) \quad$ Mean age in years (SD)

\begin{tabular}{|c|c|c|}
\hline \multicolumn{3}{|l|}{ Sex } \\
\hline Female & $119(64)$ & $38.2(13.3)$ \\
\hline Male & $68(36)$ & $43.2(14.9)$ \\
\hline \multicolumn{3}{|l|}{ Employed } \\
\hline Yes & $148(79)$ & \\
\hline Had previous episodes of acute neck pain & $118(63)$ & \\
\hline Underwent previous treatment for neck pain & $74(40)$ & \\
\hline Duration of acute neck pain shorter than 2 weeks & $79(42)$ & \\
\hline Neck pain accompanied by headache & $117(63)$ & \\
\hline On sick leave due to neck pain & $53(28)$ & \\
\hline \multicolumn{3}{|l|}{ Self-reported cause of neck pain } \\
\hline Spontaneously/unknown & $70(37)$ & \\
\hline Due to a motor vehicle accident & $42(22)$ & \\
\hline Noticed after waking up & $32(17)$ & \\
\hline After a fall or hitting the head & $13(7)$ & \\
\hline Sudden onset & $12(6)$ & \\
\hline Stress & $10(5)$ & \\
\hline Work related & $8(4)$ & \\
\hline
\end{tabular}

Follow-up questionnaires were sent out 6, 12, 26, and 52 weeks after enrolment. Patients were asked if they still had neck-pain complaints, if they consulted their GP for neck pain again, which advice was given, which medication was prescribed, and whether they had a referral for physiotherapy, complementary medicine, or further examinations. On every occasion patients completed the NDI and NRS. If a successive questionnaire was not returned within 2 weeks, the patient received a written reminder, followed by a telephone call a further 2 weeks later.

\section{Statistical analysis}

Frequencies, mean, standard deviation (SD), range, and total scores were determined for all items. All patients stating at baseline that an MVA was the cause of their current neck-pain complaints were considered to be a separate sub-group. Differences in mean scores between the MVA sub-group and the remaining cohort were calculated by means of a student $t$-test for independent samples. A $P$-value of less than $<0.05$ was used as the criterion for statistical significance although $P$ levels close to 0.05 can be best described as weak evidence of significance.

Differences between responders and nonresponders were assessed with a student $t$-test for independent samples. Non-responders were defined as patients who were approached by their GP but decided not to participate. For patients unable to answer item eight (driving) of the NDI round, figures were imputed that were close to the mean of the remaining nine items in accordance with the method proposed by Hains. ${ }^{19}$ Patients who missed two or more items were removed from the analysis. Whether dropouts during the follow-up year were selective and caused bias was evaluated separately.

Logistic regression analysis was performed with the baseline predictors as the explanatory variables and with the outcome measure 'do you still have, or are you again having, neck pain?'. Answers from the outcome measure were dichotomised. Statistical significant variables after univariate analysis $(90 \% \mathrm{Cl})$ were entered in a multivariate regression model by the backward Wald method. P-values, ORs, 95\% confidence intervals (Cls) and beta values were calculated. Negative or positive beta values refer to a negative or positive relation between an individual variable and the specific defined outcome. Nagelkerke's R-square represents the explanatory variance of the model. The last available data on recovery of every dropout was imputed. Imputing in this way is known as the 'last measurement carried forward' procedure. Logistic regression analysis was performed with available cases and also with imputed data. All statistical analyses were carried out using SPSS (version 10.0). 


\section{RESULTS}

\section{Study population}

Twenty-nine GPs enrolled patients during the recruitment period from March 2001 to August 2002. In total, 249 patients with acute neck pain were asked by their GP to join the study and were given the starting envelope. Of these, 190 patients (76\%) responded and sent back the baseline questionnaire together with a signed informed consent form. Excluded were three patients who did not meet the inclusion criteria (two patients had chronic neck pain and one was too young to participate). Finally, 187 patients formed the inception cohort.

There were significantly more male than female (51\% versus $36 \%, P<0.038$ ) non-responders ( $n=59$ ). Although non-responders were, on average, younger (36.8 versus 40.0 years), age, as well as the other variables that were taken into account, did not differ significantly. Patient characteristics are presented in Table 1.

Patients were predominantly younger females. A majority of patients $(63 \%)$ had experienced neck-pain episodes before and $40 \%$ had received previous treatments for this complaint. Mean duration of neck pain at baseline was 16 days $(S D=13.1)$ and pain at multiple sites was common, with $81 \%$ of participants having one or more complementary pain sites. MVAs formed a considerable number of self-reported causes of neck pain in this cohort (22\%) and, for $63 \%$ of patients, the neck pain was accompanied by headache.

The means of relevant variables at baseline of the MVA sub-group were compared with those of the remaining cohort. Significant results of the independent samples tests are presented in Table 2. Mean age, previous periods of neck pain, additional headache, and the mean total NDI score all differed significantly in the MVA sub-group. For sick leave there was only weak evidence that is was associated with an MVA.

The disability score (NDI) was significantly higher in the MVA sub-group at baseline. Item analysis of the NDI showed that the MVA sub-group scored significantly higher on the items regarding reading, headache, and concentration. No differences were found for the remaining variables.

\section{Follow-up}

At the 1-year follow-up, 138 patients (74\%) participated. Dropouts were almost equally distributed over the remaining cohort $(n=37 ; 27 \%)$ and the subgroup of MVA patients $(n=12 ; 28 \%)$. At the end of the follow-up period, members of the sub-group of patients who had been involved in an MVA significantly more often stated that they still had neck-pain complaints (63\% versus $40 \%)$ and had significantly
Table 2. Mean values or percentages of variables that differed significantly in the motor vehicle accident sub-group compared with the remaining cohort at baseline $(n=187)$.

\begin{tabular}{lccc} 
Variable & MVA & $\begin{array}{c}\text { Remaining } \\
\text { sub-group }(n=42)\end{array}$ & $\begin{array}{l}\text { cohort }(n=145) \\
P \text {-value }\end{array}$ \\
\hline Mean age, years & 34.8 & 41.5 & 0.007 \\
\hline On sick leave, \% & 36 & 26 & 0.037 \\
\hline Had previous neck pain periods, \% & 45 & 65 & 0.015 \\
\hline Duration of neck pain <2 weeks, \% & 58 & 44 & $0.185^{\mathrm{a}}$ \\
\hline Additional headache, \% & 86 & 56 & 0.001 \\
\hline Pain in the upper part of the neck, \% & 41 & 46 & $0.120^{\mathrm{a}}$ \\
\hline Mean score on the NRS & 6.3 & 6.5 & $0.520^{\mathrm{a}}$ \\
\hline Severe acute onset of the pain, \% & 42 & 57 & $0.758^{\mathrm{a}}$ \\
\hline Mean NDI total score & 16.6 & 13.7 & 0.018 \\
\hline
\end{tabular}

${ }^{a}$ non-significant. MVA = motor vehicle accident. NDI = neck disability index. NRS = numerical pain-rating scale.

higher mean scores on the NDI (11.0 versus 7.1$)$ compared with the remaining cohort.

\section{Prognostic factors}

The outcome variable evaluated was continuous neck pain. Univariate regression analysis revealed seven items that were significantly correlated with outcome and, after multivariate analysis, three items remained (Table 3). Age and sex were corrected for by including those variables in the final analysis. The explanatory variance of the model (R-square) was $30 \%$.

The two variables with the strongest positive correlation with continuous neck pain were selfreported MVA at baseline and duration of neck pain

Table 3. Prognostic factors significantly correlated with continuous neck pain after 1 -year follow-up by univariate $(P<0.1)$ and multivariate $(P<0.05)$ logistic regression analysis $(n=138)$.

\begin{tabular}{lcccc} 
& Univariate analysis & Multivariate analyses \\
\cline { 2 - 5 } Item & $\beta$ & $\begin{array}{c}\text { OR } \\
(90 \% \mathrm{Cl})\end{array}$ & $\beta$ & $\begin{array}{c}\text { OR } \\
(95 \% \mathrm{Cl})\end{array}$ \\
\hline Treated by physiotherapist before & 0.2 & $\begin{array}{c}1.28 \\
(1.00 \text { to } 1.64)\end{array}$ & \\
\hline Mean score on the NRS & 0.2 & $\begin{array}{c}1.24 \\
(1.02 \text { to } 1.51)\end{array}$ & \\
\hline Pain in the upper part of the neck & 0.4 & $\begin{array}{c}1.48 \\
(1.17 \text { to } 1.87)\end{array}$ & 0.5 & $(1.25$ to 2.12$)$ \\
\hline Additional headache & 1.0 & $\begin{array}{c}2.71 \\
(1.33 \text { to } 5.51)\end{array}$ & & \\
\hline Duration of complaints $>2$ weeks & 1.2 & $\begin{array}{c}3.36 \\
(1.62 \text { to } 6.94)\end{array}$ & 1.7 & $(2.24$ to 12.6) \\
\hline Motor vehicle accident & 0.9 & $\begin{array}{c}2.51 \\
(1.09 \text { to } 5.80)\end{array}$ & 1.7 & $(1.90$ to 15.0) \\
\hline Total score on the NDI & 0.1 & $\begin{array}{c}1.07 \\
(1.01 \text { to } 1.13)\end{array}$ & \\
\hline
\end{tabular}

$N D I=$ neck disability index. NRS $=$ numerical pain-rating scale. $O R=$ odds ratio. 
complaints being longer than 2 weeks at the first consultation. Pain in the upper part of the neck also had a significant positive association with outcome. As inputting the last available data on recovery of 13 dropouts $(7 \%)$ in a 'last measurement carried forward' procedure did not significantly change the results, the data on available cases is presented only.

\section{DISCUSSION}

\section{Summary of main findings}

Patients experienced higher levels of continuous neck pain and disability after an MVA compared with patients who had not reported such an accident. An MVA seems also to be an important independent prognostic factor for continuous neck pain.

\section{Strengths and limitations of the study}

This study has some limitations. For instance, the sample size is small and, therefore, external validity may be limited. Studies with larger numbers of patients are necessary to gain a more precise insight into the differences between the two sub-groups. A logical third sub-group for comparison purposes would have included patients with acute neck pain following a non-MVA-related injury but insufficient numbers of these patients were gathered to create an acceptable sub-group. The results presented may, in some respect, be flawed by non-response. Nonresponders were mainly younger males. This finding has been reported before..$^{20}$

Due to this selective non-response and somewhat incomplete follow-up, the generalisability of the results is limited. However, the number of dropouts was limited and almost equally divided over both subgroups and the input of data did not reveal significant differences.

The study queried whether the percentage of patients who had been involved in an MVA in the cohort of participants with acute neck pain $(23 \%)$ was representative of GPs' daily practice. An MVA is not the same as a whiplash-type injury but neck pain as a result of an MVA is a well-known disorder in the general population and most patients would be well aware of the condition. In addition, it could be that the emotionally charged concept of whiplash stimulates patients to visit their GP, resulting in selection bias and over-representation in this cohort. However, a patient population with a wide range of self-reported causes has the potential to be very heterogeneous. This study consisted of patients with a variety of self-reported causes, thereby representing the wide spectrum of patients' characteristics for general practice.

\section{Comparison with existing literature}

This study showed that the percentage of patients who had been involved in an MVA and reported continuous neck pain was significantly higher than for those patients with other self-reported causes of neck pain. Reported prevalences of continuous neck pain in patients who had experienced MVAs vary widely in the literature and seem to consist of two different groups of figures - lower prevalence figures of chronic neck pain range between $8 \%$ and $24 \%,{ }^{21}$ while higher reported figures range from $43 \%$ up to $66 \%{ }^{22,23}$ Marshall reported that even $80 \%$ of patients experienced neck discomfort after an MVA. ${ }^{12}$

It is difficult to give a direct explanation for this apparent dualism in presented figures. The heterogeneity in study design, duration of follow-up, setting, and chosen outcome makes it difficult to compare these results with each other. One reason for the variation could be the definition of chronicity that is used. The outcome measures of 'chronic pain' and 'recovery' are not interchangeable and are each related to different perspectives of the same situation. In general, chronicity is defined as the persistence of symptoms for more than 3 months. Subsequent episodes of neck pain can be new or recurrent and the link with chronicity is not simple. A pattern of recurrence and intermittent pain may be a more realistic description of a patient's experience after an MVA than the presence of continuous symptoms. ${ }^{20}$

It is important to remember that it is not exclusively MVAs that seem to be associated with chronic neck pain, but all types of neck trauma. ${ }^{3}$ The reason why a higher percentage of patients experience chronic neck pain after an MVA is still being debated.

Self-reported pain in the upper part of the neck was also a significant item in the final model. This finding may represent a link with the often-reported headache in patients who have whiplash. Zygapophyseal joint pain has been suggested as the single most-common basis for chronic neck pain and it might be responsible for many of the headaches. ${ }^{24}$ The Cervicogenic Headache International Study Group concluded that headache arising from the upper part of the neck is one of the three major criteria for the diagnosis, ${ }^{25}$ a finding that could have consequences for treatment modalities in general practice and can be implemented in routine examination after an MVA.

The duration of complaints being longer than 2 weeks is also of prognostic value. This item remained by logistic regression analysis in the final model. In the study by Jónsson et al all patients who were symptomatic after 6 weeks still had complaints at the 1year and 5-year follow-ups. ${ }^{23}$

This study shows that an MVA forms a major factor in predicting a higher chance of developing chronic neck pain. Although there is still a difference of opinion on this aspect, more authors - in the last few years in particular - have reported on this association. ${ }^{3,6}$ Contrary to prior belief, most individuals with neck pain 
do not experience complete resolution of their symptoms and disability. According to the 2007 guidelines of the New South Wales Motor Accidents Authority in Australia, most patients can expect a favourable outcome but recurrences are common and $10 \%$ can have persistent problems. ${ }^{26}$ This still represents a view that is too optimistic.

The usefulness of the NDI for the assessment of disability has been advocated before. ${ }^{27}$ In a 3-year prospective study on the prediction of long-term health problems after an MVA from three simple questionnaires, only the NDI was significantly related to outcome. ${ }^{27}$ The authors concluded that the analysis of the decrease of the level of activities obtained by NDI provides a tool to identify individuals at risk. Using the $\mathrm{NDI}$ as the measure of disability enabled demonstration of significant differences between the sub-group of patients who had had an MVA and the remaining cohort at baseline and after 1-year follow-up.

\section{Implications for future research and practice}

MVAs are an important factor for acute neck pain in general practice. The findings of this study stress the fact that patients who have experienced MVAs constitute a separate sub-group and may be subject to long-lasting neck pain and disability. The dualism in presented causes (traumatic and non-traumatic) and their consequences for the clinical course of neck pain is important and must be borne in mind. In daily practice, a more active approach to assessment of this particular sub-group could help to prevent chronicity. An active approach entails encouraging the patient to stay active, to avoid sick leave and bed rest, and to develop an active coping strategy according to the principles of graded activity.

Evidence for the efficacy of measures taken by a GP is still absent and, as such, future research is required to find proof for strategies that are effective in reducing the chances of acute neck pain becoming chronic. Evaluating an active approach by GPs with an emphasis on patient education for sub-groups of patients at risk of developing chronic neck pain would be of interest.

\section{Funding body}

Pijnkenniscentrum Erasmus University Medical Centre Rotterdam (09.199.01)

\section{Ethical approval}

Approval for this study was obtained from the Ethical Committee of the Erasmus University Medical Centre, (MEC 193.633/2000/150)

\section{Competing interests}

The authors have stated that there are none.

\section{Discuss this article}

Contribute and read comments about this article on the Discussion Forum: http://www.rcgp.org.uk/bjgp-discuss

\section{REFERENCES}

1. Douglass AB, Bope ET. Evaluation and treatment of posterior neck pain in family practice. J Am Board Fam Pract 2004; 17(Suppl): S13-S22.

2. Côté P, Cassidy JD, Carroll L. The factors associated with neck pain and its related disability in the Saskatchewan population. Spine 2000 25(9): 1109-1117.

3. Guez M, Hildingsson C, Stegmayr B, Toolanen G. Chronic neck pain of traumatic and non-traumatic origin: a population-based study. Acta Orthop Scand 2003; 74(5): 576-579.

4. Mäkelä M, Heliövaara M, Sievers K, et al. Prevalence, determinants, and consequences of chronic neck pain in Finland. Am J Epidem 1991; 134(11): 1356-1367.

5. Picavet HS, Schouten JS. Musculoskeletal pain in the Netherlands: prevalences, consequences and risk groups, the DMC(3)-study. Pain 2003; 102(1-2): 167-178.

6. Bunketorp L, Stener-Victorin E, Carlsson J. Neck pain and disability following motor vehicle accidents: a cohort study. Eur Spine J 2005; 14(1): 84-89.

7. Herrström P, Lannerbro-Geijer G, Högstedt B. Whiplash injuries from car accidents in a Swedish middle-sized town during 1993-95. Scand J Prim Health Care 2000; 18(3): 154-158.

8. Wismans KSHM, Huijkens CG. Incidentie en prevalentie van het 'whiplash' trauma. TNO Report RBV.041.1/JW. Delft: Road Vehicle Research Institute, 1994

9. Cassidy JD, Carroll LJ, Côte P, et al. Effect of eliminating compensation for pain and suffering on the outcome of insurance claims for whiplash injury. New Eng J Med 2000; 342(16): 1179-1186.

10. Barnsley L, Lord S, Bogduk N. Whiplash injury: clinical review. Pain 1994; 58(3): 283-307.

11. Schrader H, Obelieniene D, Bovim G, Surkiene D, et al. Natural evolution of late whiplash syndrome outside the medicolegal context. Lancet 1996; 347(9010): 1207-1211.

12. Marshall PD, O'Connor M, Hodgkinson JP. The perceived relationship between neck symptoms and precedent injury. Injury 1995; 26(1): $17-19$.

13. Bunketorp L, Nordholm L, Carlsson J. A descriptive analysis of disorders in patients 17 years following motor vehicle accidents. Eur Spine J 2002; 11(3): 227-234.

14. Spitzer WO, Skovron ML, Salmi LR, et al. Scientific monograph of the Quebec Task Force on Whiplash-Associated Disorders: redefining 'whiplash' and its management. Spine 1995; 20(8 Suppl): 1S-73S.

15. Harder S, Veilleux M, Suissa S. The effect of socio-demographic and crash-related factors on the prognosis of whiplash. J Clin Epidemiol 1998; 51(5): 377-384.

16. Gargan MF, Bannister GC. The rate of recovery following whiplash injury. Eur Spine J 1994; 3(3): 162-164.

17. Scholten-Peeters GG, Verhagen AP, Bekkering GE, et al. Prognostic factors of whiplash-associated disorders: a systematic review of prospective cohort studies. Pain 2003; 104(1-2): 303-322.

18. Ameratunga SN, Norton RN, Bennett DA, Jackson RT. Risk of disability due to car crashes: a review of the literature and methodological issues. Injury 2004; 35(11): 1116-1127.

19. Hains F, Waalen J, Mior S. Psychometric properties of the neck disability index. J Manipulative Physiol Ther 1998; 21(2): 75-80.

20. Croft PR, Lewis M, Papageorgiou AC, et al. Risk factors for neck pain: a longitudinal study in the general population. Pain 2001; 93(3): $317-325$.

21. Obelieniene D, Schrader H, Bovim G, et al. Pain after whiplash: a prospective controlled inception cohort study. J Neurol Neurosurg Psychiatry 1999; 66(3): 279-283.

22. Gureje O, Simon GE, Von Korff M. A cross-national study of the course of persistent pain in primary care. Pain 2001; 92(1-2): 195-200.

23. Jónsson H Jr, Cesarini K, Sahlstedt B, W. Findings and outcome in whiplash-type neck distorsions. Spine 1994; 19(24): 2733-2743.

24. Barnsley L, Lord S, Wallis BJ, Bogduk N. The prevalence of chronic zygapophysial joint pain after whiplash. Spine 1995; 20(1): 20-26.

25. Sjaastad O, Frediriksen TA, Pfaffenrath V. Cervicogenic headache: diagnostic criteria. The Cervicogenic Headache International Study Group. Headache 1999; 38(6): 442-445.

26. New South Wales Motor Accidents Authority. 2nd edition. Guidelines for the Management of Acute Whiplash-associated Disorders for Health Professionals. Sydney: New South Wales Motor Accidents Authority, 2007.

27. Miettinen T, Leino E, Airaksinen O, Lindgren KA. The possibility to use simple validated questionnaires to predict long-term health problems after whiplash injury. Spine 2004; 29(3): E47-E51. 